\title{
Cytokinin Dynamics during the Response to Nitrogen in Two Contrasting Plectranthus Genotypes
}

\author{
Ellen T. Paparozzi ${ }^{3}$ and Jazbaat K. Chahal ${ }^{1}$ \\ Department of Agronomy and Horticulture, University of Nebraska-Lincoln, Lincoln, NE 68583-0724
}

Petre Dobrev

Institute of Experimental Botany AS CR, Rozvojova 263, 16502 Prague 6, Czech Republic

Elizabeth A. Claassen ${ }^{2}$

Department of Statistics, University of Nebraska-Lincoln, Lincoln, NE 68583-0963

Walter W. Stroup

Department of Statistics, University of Nebraska-Lincoln, Lincoln, NE 68583-0963

Radomira Vankova

Institute of Experimental Botany AS CR, Rozvojova 263, 16502 Prague 6, Czech Republic

\begin{abstract}
AdDitional INDEX words. abscission, chlorophyll, cytokinin, leaf regreening, swedish ivy, nitrogen stress
Abstract. Nitrogen response was compared in two Plectranthus species, Plectranthus parviflorus and Plectranthus ambiguus, which differ substantially in their phenotypic reaction to nitrogen limitation. The leaves of the former species gradually yellow during the nitrogen stress but are retained on the plant. This species copes with nitrogen deficiency also by gradual hydrolysis of starch grains. The latter species, $P$. ambiguus, responds by abscission of lower leaves. As plant hormones cytokinins are involved in nitrogen response as well as in regulation of the chlorophyll content, their dynamics were followed to explore the fast responses as well as the impact of nitrogen treatment. Both plant species responded to nitrogen deficiency/supplementation in similar ways, by downregulation and upregulation, respectively, of active cytokinins. However, the different phenotypic reactions imposed by nitrogen limitation were associated with specific regulation of cytokinin pool accompanying the stress response by the two species. The increase of the active cytokinins on nitrogen resupply was faster and stronger in the regreening species, $P$. parviflorus than in $P$. ambiguus. However, the $P$. ambiguus plants maintained higher basal levels of all cytokinin metabolites as well as chlorophyll content when compared with $P$. parviflorus. Nitrogen deficiency was associated in this species with accumulation of cis-zeatin-type cytokinins, which preceded abscission of lower and later on of middle leaves. The achieved results indicate that phenotypic variations in the response to nitrogen deficiency/supplementation are associated with significant quantitative and qualitative differences in the cytokinin pool.
\end{abstract}

Nutrient availability strongly affects plant growth and development. To adapt to environmental conditions, which may cause considerable fluctuation in nutrient levels and accessibility, plants have evolved the ability to sense nutrients, regulate their uptake and assimilation as well as modulate root architecture to proliferate in nutrient-rich zones (Ruffel et al., 2011). One of the key growth-limiting nutrients is $\mathrm{N}$ and plants have adopted different strategies to cope with its limitation. Recently, we described that $P$. parviflorus (swedish ivy) responds to $\mathrm{N}$ deficiency by yellowing of leaves and cessation of growth to such an extent that the plant appears dormant (Korus et al., 2010). However, no leaves are lost.

\footnotetext{
Received for publication 4 Dec. 2015. Accepted for publication 19 Feb. 2016. This research was supported in part by The Fleming Research Fund and the University of Nebraska Agricultural Research Division Hatch Project NEB-22-341. The authors thank Dr. Paul Staswick and Dr. Gautam Sarath for critical review of this manuscript.

${ }^{1}$ Former graduate research assistant.

${ }^{2}$ Former graduate assistant Department of Statistics; current address SAS Institute, Cary, NC.

${ }^{3}$ Corresponding author. E-mail: etp1@unl.edu.
}

On reintroduction of $\mathrm{N}$ to the system, the existing leaves regreen and new growth will ensue within 4 weeks. The regreening can happen repeatedly. However, another species of this genus, $P$. ambiguus, responds differently and more typically to $\mathrm{N}$ deficiency. Within 4 weeks of $\mathrm{N}$ limitation, leaves will abscise and reintroduction of $\mathrm{N}$ will then cause development of new leaves from terminal meristems and axillary buds.

Plant responses to $\mathrm{N}$ deficiency are mediated by plant hormones, especially by cytokinins (Argueso et al., 2009; Kiba et al., 2011). As cytokinins, often referred to as the leaf regreening hormone, also exhibit positive effects on chlorophyll concentration in leaves we decided to compare the dynamics of the response to $\mathrm{N}$ deficiency and subsequent $\mathrm{N}$ resupply by $P$. parviflorus and $P$. ambiguus at the level of chlorophyll and endogenous cytokinin metabolites.

\section{Materials and Methods}

Plant material and eXPerimental SetuP. Four experiments were conducted from Fall 2008 through Spring 2010. The first 
two preliminary experiments allowed determination of the pattern and differential response of the two species over the 6 -week period. In addition, previous research showed that $\mathrm{N}$ concentration in leaves was $0.02 \% \pm 0.01$ when $\mathrm{N}$ was absent and $5.98 \%$ to $7.26 \%$ when $\mathrm{N}$ was present. For each of the two final experiments, 24 pencil-sized cuttings of similar length with a five nodes from each of the two species, $P$. parviflorus and $P$. ambiguus, were rooted in vermiculite for 3-4 weeks. Stock plants of both species were well fertilized and showed no deficiencies. The cuttings were treated with rooting powder containing $0.3 \%$ indole-3-butyric acid (Hormex; Brooker Chemicals, Chatsworth, CA) before sticking and flats were placed under intermittent mist which was set to a 4-s burst every $20 \mathrm{~min}$ from $1 \mathrm{~h}$ after sunrise to $1 \mathrm{~h}$ before sunset. Supplemental incandescent light (75 W) was applied regularly from 2200 to $0200 \mathrm{HR}$ to prevent flowering. The cuttings received no supplemental nutrients during rooting.

On rooting, one or two plants were set into a hydroponics setup which consisted of 24 7.6-L containers, tightly closed to prevent light transmittance. Each container had a lid of expanded foam insulation with two holes to hold the plant and the air hose. A large gauge hypodermic needle at the end of each air hose was attached to a center hose to provide a continuous aeration. The greenhouse temperature was $21-27{ }^{\circ} \mathrm{C}$ day and $16-18{ }^{\circ} \mathrm{C}$ night. Supplementation of incandescent light from 2200 to 0200 HR continued. The plants were in hydroponics for a total of 6 weeks (two experimental periods of 3 weeks each).

The duration of treatments and number of plants per pot was optimized in two preliminary experiments. For color, the color readings from the Royal Horticultural Society Color Chart (RHS, London, UK) were used so that when the plants that received $0 \mathrm{mg} \cdot \mathrm{L}^{-1} \mathrm{~N}$ exhibited a change in color to yellow-green (RHS Color Chart 144A) and plants that

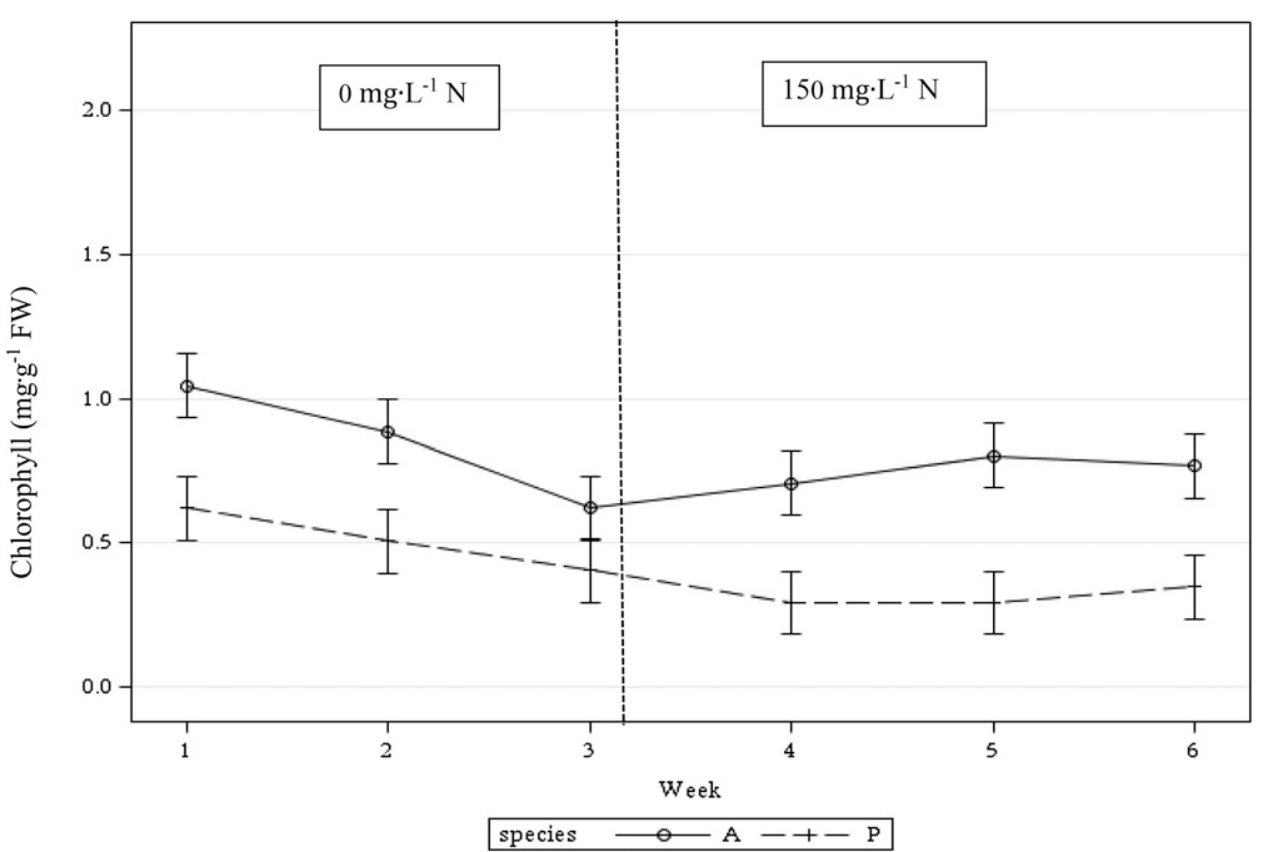

Fig. 1. Changes in chlorophyll concentration in leaves of Plectranthus parviflorus (P) and Plectranthus ambiguus (A) in response to changes in $\mathrm{N}$ concentration over a 6-week period. The three-way interaction of species by treatment by week was statistically significant indicating that over the 6-week period each species responded differently to the presence or absence of $\mathrm{N}$. The error bars indicate the error associated with mean for the chlorophyll measurements for a given week. The SE of the difference in leaf chlorophyll concentration between weeks for each species $=0.078 \mathrm{mg} \cdot \mathrm{g}^{-1} \mathrm{FW}$. While leaf chlorophyll concentrations for either cultivar did not return to initial values, both species looked visually green as measured using the Royal Horticultural Society Color Chart (RHS, London, UK).

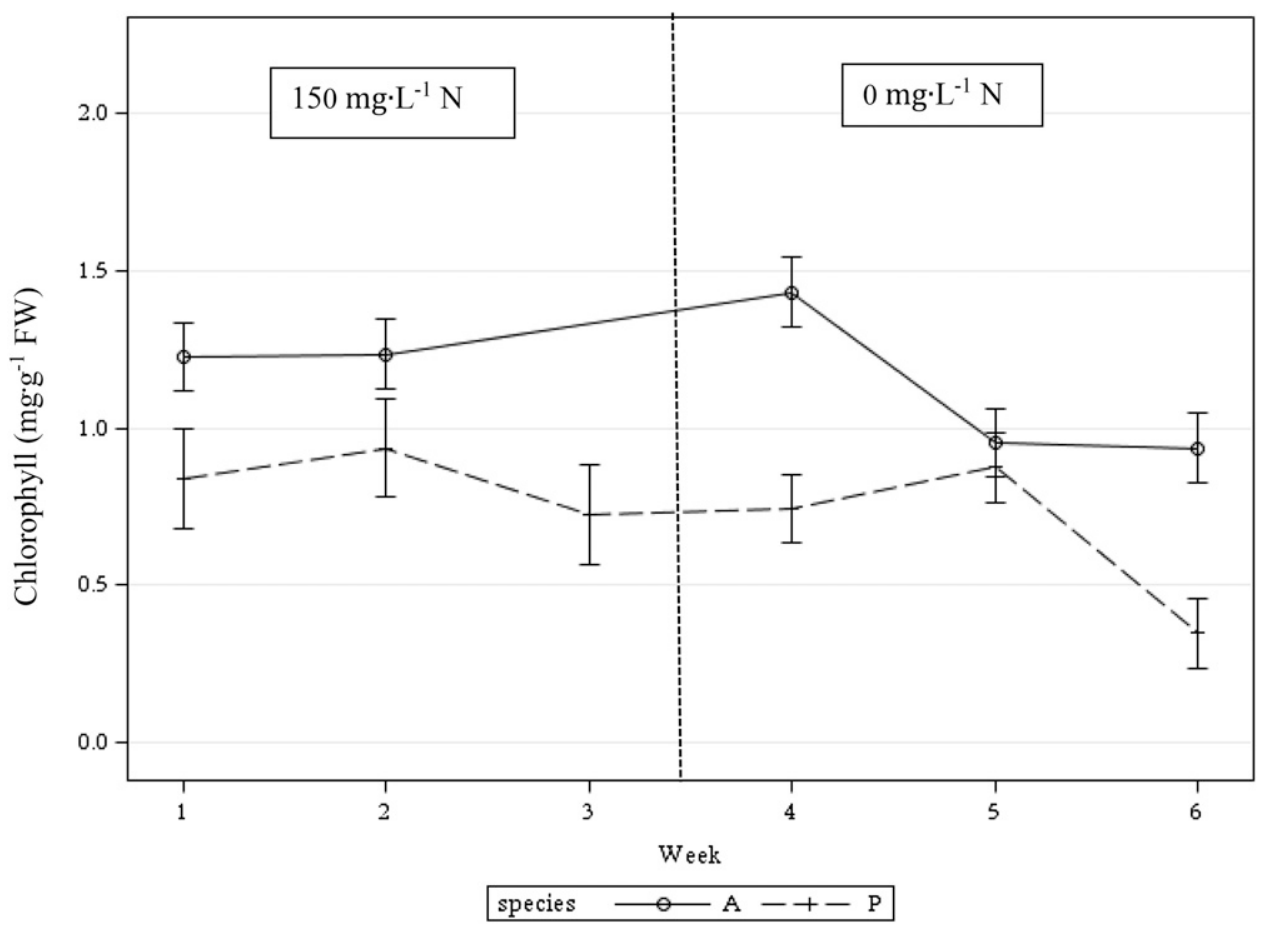

Fig. 2. Changes in chlorophyll concentration in leaves of Plectranthus parviflorus $(\mathrm{P})$ and Plectranthus ambiguus (A) in response to changes in $\mathrm{N}$ concentration over a 6-week period. The three-way interaction of species by treatment by week was statistically significant indicating that over the 6-week period each species responded differently to the presence or absence of $\mathrm{N}$ with a decrease in leaf chlorophyll concentration happening 1 week earlier in P. ambiguus as compared with P. parviflorus. The error bars indicate the error associated with mean for the chlorophyll measurements for a given week. The SE of the difference in leaf chlorophyll concentration between weeks for each species $=0.078 \mathrm{mg} \cdot \mathrm{g}^{-1} \mathrm{FW}$. 
received $150 \mathrm{mg} \cdot \mathrm{L}^{-1} \mathrm{~N}$ were $137 \mathrm{~A}$ (green), the one-time switch of treatments was done. This occurred after 3 weeks. The number of plants per pot depended on whether the plants received $\mathrm{N}$ or not. Any plant receiving $\mathrm{N}$, had lower axillary bud growth such that plants had multiple terminals for sampling. If $\mathrm{N}$ was withheld extensively, two plants were needed to have pairs of leaves to sample each week-one plant for the first 3 weeks (period 1) and one plant for the next 3 weeks (period 2).

The $0 \mathrm{mg} \cdot \mathrm{L}^{-1} \mathrm{~N}$ solution consisted of $48.5 \mathrm{mg} \cdot \mathrm{L}^{-1} \mathrm{Ca}$ $\left(\mathrm{CaCl}_{2} \cdot 2 \mathrm{H}_{2} \mathrm{O}\right) ; 24.3 \mathrm{mg} \cdot \mathrm{L}^{-1} \mathrm{Mg}$ and $32 \mathrm{mg} \cdot \mathrm{L}^{-1} \mathrm{~S}\left(\mathrm{MgSO}_{4} \cdot 7 \mathrm{H}_{2} \mathrm{O}\right)$; $75 \mathrm{mg} \cdot \mathrm{L}^{-1} \mathrm{P}$ and $94.7 \mathrm{mg} \cdot \mathrm{L}^{-1} \mathrm{~K}$ $\left(\mathrm{KH}_{2} \mathrm{PO}_{4}\right)$. The composition of the $150 \mathrm{mg} \cdot \mathrm{L}^{-1} \mathrm{~N}$ solution was 53 $\mathrm{mg} \cdot \mathrm{L}^{-1}\left(\mathrm{KNO}_{3}\right)$ plus $96 \mathrm{mg} \cdot \mathrm{L}^{-1} \mathrm{~N}$ $\left(\mathrm{NH}_{4} \mathrm{NO}_{3}\right) ; 48.5 \mathrm{mg} \cdot \mathrm{L}^{-1} \mathrm{Ca}$ and 75 $\mathrm{mg} \cdot \mathrm{L}^{-1} \mathrm{P}\left[\mathrm{Ca}\left(\mathrm{H}_{2} \mathrm{PO}_{4}\right)_{2} \cdot \mathrm{H}_{2} \mathrm{O}\right] ; 24.3$ $\mathrm{mg} \cdot \mathrm{L}^{-1} \quad \mathrm{Mg}$ and $32 \mathrm{mg} \cdot \mathrm{L}^{-1}$ $\left(\mathrm{MgSO}_{4} \cdot 7 \mathrm{H}_{2} \mathrm{O}\right)$ and $150 \mathrm{mg} \cdot \mathrm{L}^{-1} \mathrm{~K}$ $\left(\mathrm{KNO}_{3}\right)$. Thus, concentrations of all macroelements except $\mathrm{N}$ and $\mathrm{K}$ were the same. Both solutions contained the same microelement concentration: $0.50 \mathrm{mg} \cdot \mathrm{L}^{-1} \mathrm{~B}, 0.02$ $\mathrm{mg} \cdot \mathrm{L}^{-1} \mathrm{~N} \mathrm{Cu}\left(\mathrm{Cu}\right.$ EDTA), $1 \mathrm{mg} \cdot \mathrm{L}^{-1}$ $\mathrm{Fe}^{3+}$ (Fe EDTA), $0.50 \mathrm{mg} \cdot \mathrm{L}^{-1} \mathrm{Mn}$ (Mn EDTA), $0.05 \mathrm{mg} \cdot \mathrm{L}^{-1} \mathrm{Zn}(\mathrm{Zn}$ EDTA), and $0.01 \mathrm{mg} \cdot \mathrm{L}^{-1} \mathrm{Mo}$ $\left(\mathrm{Na}_{2} \mathrm{MoO}_{4} \cdot 2 \mathrm{H}_{2} \mathrm{O}\right)$. The $\mathrm{pH}$ of the solutions was adjusted to 6.0 using $1 \mathrm{~m} \mathrm{KOH}$. All solutions were changed when either the $\mathrm{pH}$ changed by 1 unit or when the level of the solution dropped (at least one change per week).

Chlorophyll aNalysis. Weekly, one fully expanded leaf starting from the first pair down from the terminal whorl was sampled for chlorophyll determination, which was done immediately, using acetone extraction (Arnon, 1949). In plants which did not grow, the second and third pairs were sampled and then the second plant was used. About 100-200 mg of the leaf tissue without the midvein were ground in $20 \mathrm{~mL}$ of $80 \%$ acetone using a mortar and pestle for $5 \mathrm{~min}$. The solution was then filtered into a test tube. The filtered extract was then poured into a fresh cuvette and placed in the spectrophotometer to record the absorbance at $663 \mathrm{~nm}$. The chlorophyll a and b contents were

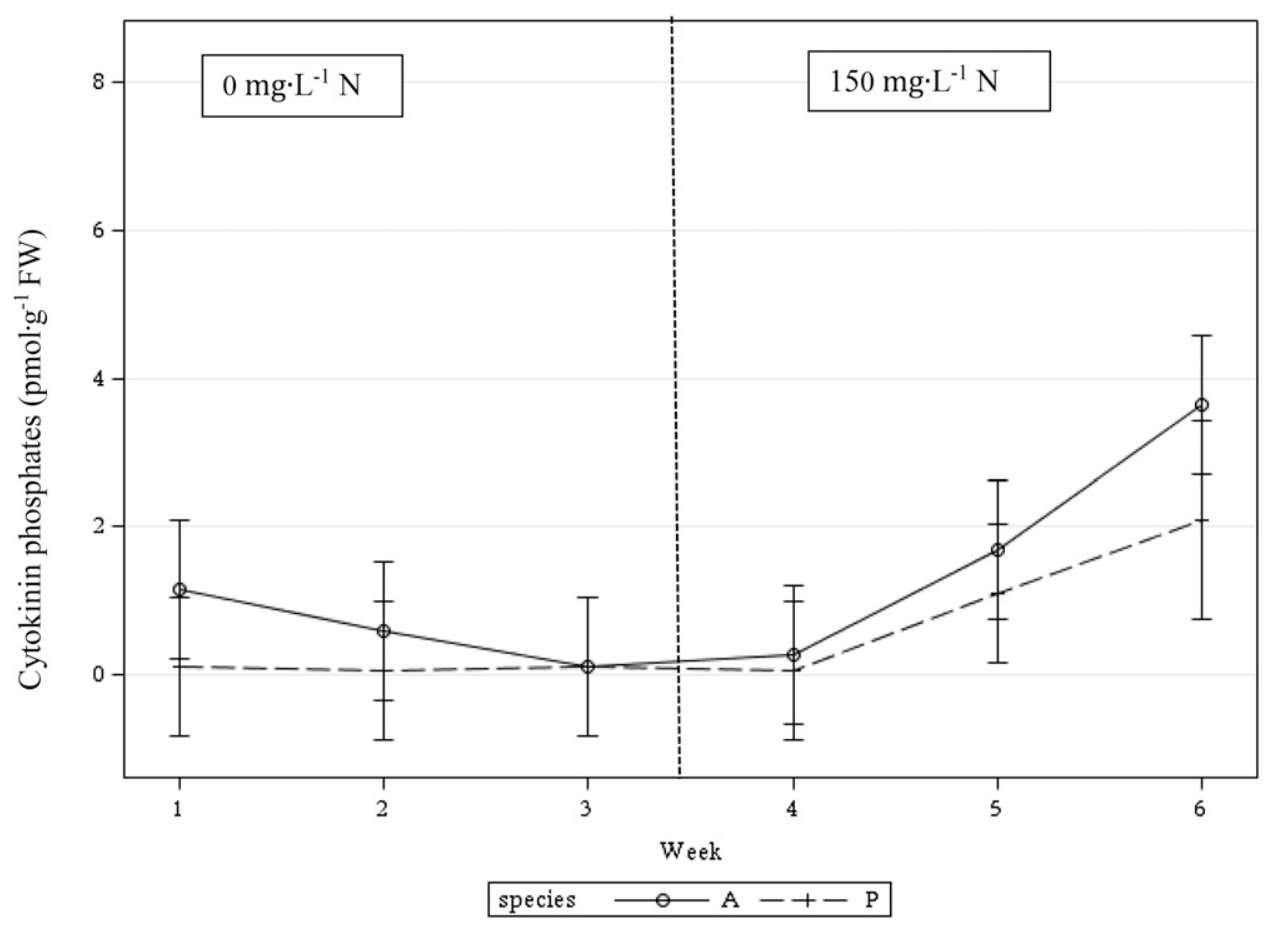

Fig. 3. Changes in biosynthetic precursor content in leaves of Plectranthus parviflorus $(\mathrm{P})$ and Plectranthus ambiguus (A) in response to changes in $\mathrm{N}$ concentration over a 6-week period. The three-way interaction of species by treatment by week was statistically significant indicating that over the 6-week period each species responded differently to the presence or absence of $\mathrm{N}$ as evidenced by a stable level of precursors in P. parviflorus when no $\mathrm{N}$ was present vs. a reduction in precursors in leaves of $P$. ambiguus. Upon addition of $\mathrm{N}$, precursor content increased in both species. The error bars indicate the error associated with mean for the cytokinin measurements for a given week. The SE of the difference in leaf precursor content between weeks for each species $=0.623 \mathrm{pmol} \cdot \mathrm{g}^{-1} \mathrm{FW}$.

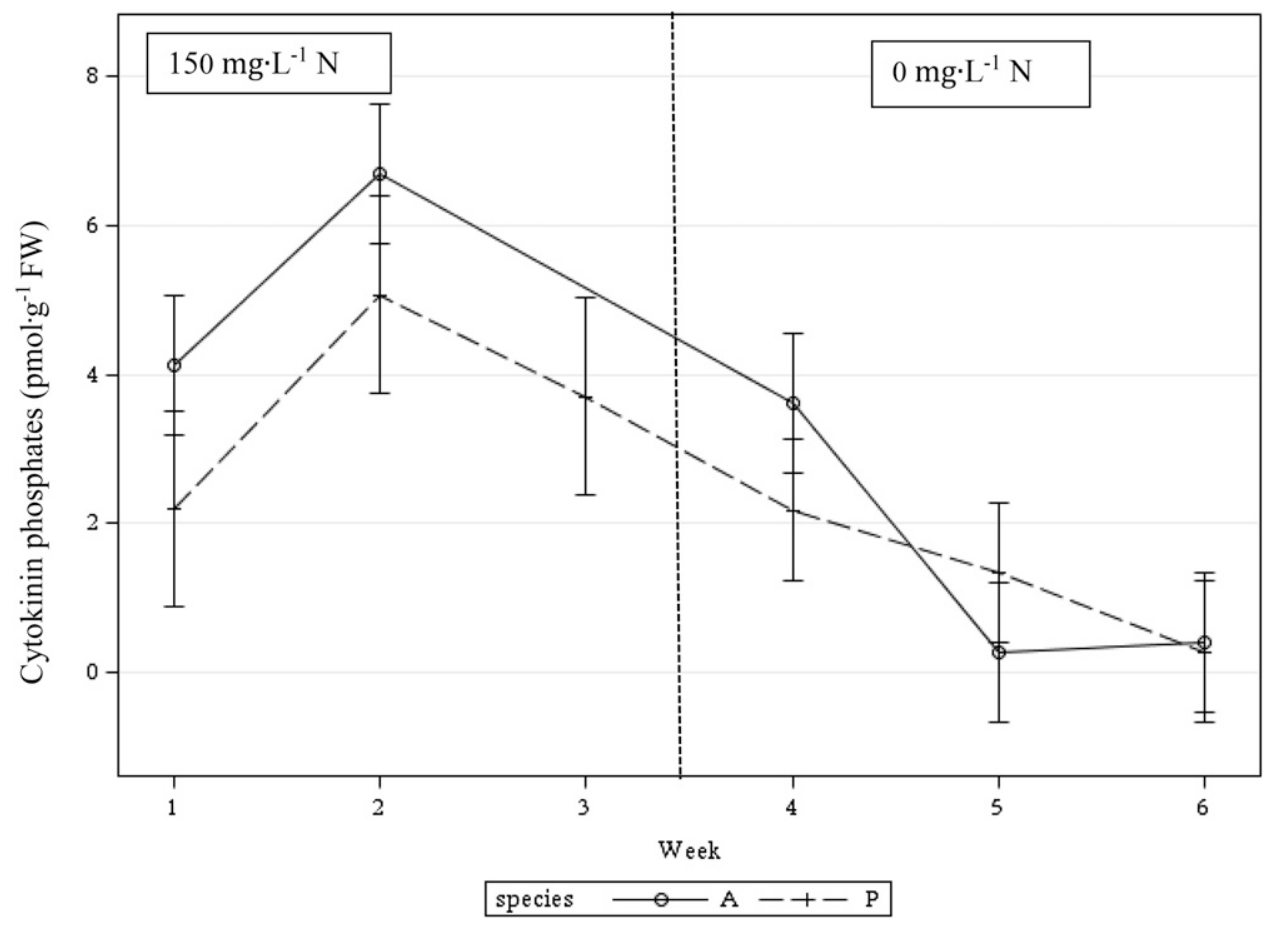

Fig. 4. Changes in biosynthetic precursor content in leaves of Plectranthus parviflorus $(\mathrm{P})$ and Plectranthus ambiguus (A) in response to changes in $\mathrm{N}$ concentration over a 6-week period. The three-way interaction of species by treatment by week was statistically significant indicating that over the 6-week period each species responded differently to the presence or absence of $\mathrm{N}$ in that upon removal of $\mathrm{N}$ a dramatic drop in precursor content occurred in leaves of $P$. ambiguus occurred at week 5 . The error bars indicate the error associated with mean for the cytokinin measurements for a given week. The SE of the difference in leaf precursor content between weeks for each species $=0.662 \mathrm{pmol} \cdot \mathrm{g}^{-1} \mathrm{FW}$. 
evaluated spectrophotometrically at 663 and $645 \mathrm{~nm}$. Chlorophyll a, chlorophyll $\mathrm{b}$, and total chlorophyll concentrations were calculated using Arnon's equation (Arnon, 1949).

Cytokinin analysis. For cytokinin analysis, the other fully expanded leaf from the first pair down from the terminal whorl was cut into thin strips 2-3 mm wide along the length of the leaf. Each sample was weighed, flash frozen with liquid $\mathrm{N}$ and stored in precooled plastic tubes at $-80{ }^{\circ} \mathrm{C}$. Samples were lyophilized. Cytokinins were extracted and purified according to Dobrev and Kaminek (2002). Samples $(\approx 300 \mathrm{mg}$ FW) were homogenized and extracted twice with methanol/water/formic acid (15:4:1, by volume). Deuteriumlabeled standards ( $50 \mathrm{pmol}$ of each) were added. The active cytokinins were trans-zeatin, $\left[{ }^{2} \mathrm{H}_{5}\right] \mathrm{Z}$; trans-zeatin riboside, $\left[{ }^{2} \mathrm{H}_{5}\right] \mathrm{Z} 9 \mathrm{R}$; isopentenyladenine, $\left[{ }^{2} \mathrm{H}_{6}\right] \mathrm{iP}$; isopentenyladenosine, $\left[{ }^{2} \mathrm{H}_{6}\right] \mathrm{iP9R}$; dihydrozeatin, $\left[{ }^{2} \mathrm{H}_{3}\right] \mathrm{DHZ}$; dihydrozeatin riboside, $\left[{ }^{2} \mathrm{H}_{3}\right] \mathrm{DHZ} 9 \mathrm{R}$. The conjugates were a) N-glucosides: trans-zeatin N7-glucoside, $\left[{ }^{2} \mathrm{H}_{5}\right] \mathrm{Z7G}$; trans-zeatin N9-glucoside, $\left[{ }^{2} \mathrm{H}_{5}\right] \mathrm{Z} 9 \mathrm{G}$; isopentenyladenine N7-glucoside, $\left[{ }^{2} \mathrm{H}_{6}\right] \mathrm{iP} 7 \mathrm{G}$; isopentenyladenine N9-glucoside, $\left[{ }^{2} \mathrm{H}_{6}\right] \mathrm{iP9G}$; dihydrozeatin N9-glucoside, $\left[{ }^{2} \mathrm{H}_{3}\right]$ DHZ9G and b) O-glucosides: trans-zeatin O-glucoside, $\left[{ }^{2} \mathrm{H}_{5}\right] \mathrm{ZOG}$; trans-zeatin riboside O-glucoside, $\left[{ }^{2} \mathrm{H}_{5}\right] \mathrm{Z9ROG}$; dihydrozeatin O-glucoside, $\left[{ }^{2} \mathrm{H}_{7}\right] \mathrm{DHZOG}$ (Apex Organics, Honiton, UK). The cis-zeatin derivatives were determined from the retention time and the mass spectra of unlabeled standards and response ratio of their trans-zeatin counterparts. To get rid of some hydrophobic compounds, extracts were purified using a SPE-C18 column (SepPak-C18; Waters, Milford, MA), evaporated under vacuo into water phase, diluted with formic acid and separated on a reverse phasecation exchange SPE column (Oasis-MCX; Waters). The cytokinin nucleotides were eluted with $0.35 \mathrm{M} \mathrm{NH}_{4} \mathrm{OH}$ in water, cytokinin bases, ribosides and glucosides were eluted with $0.35 \mathrm{M} \mathrm{NH}_{4} \mathrm{OH}$ in $70 \%$ methanol. Nucleotide fraction was treated with alkaline phosphate and evaporated. Cytokinin

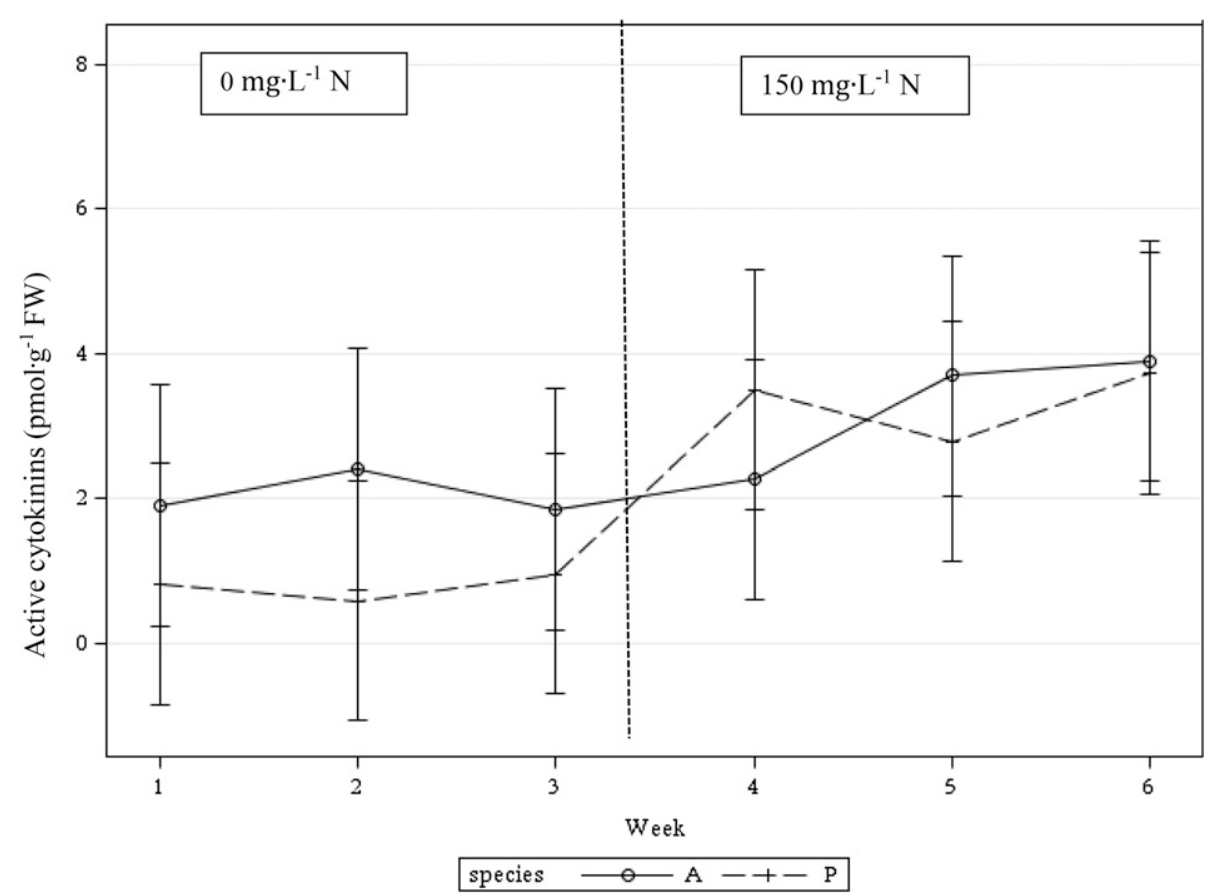

Fig. 5. Changes in the physiologically active cytokinin content in leaves of Plectranthus parviflorus (P) and Plectranthus ambiguus (A) in response to changes in $\mathrm{N}$ concentration over a 6-week period. The interaction of treatment by week was statistically significant indicating that both species reacted similarly to the presence or absence of $\mathrm{N}$ but how both species responded was different over the 6-week period. Leaves of P. parviflorus showed an increase in physiologically active cytokinin content after only 1 week of $\mathrm{N}$ and then did not increase, while leaves of $P$. ambiguus showed an increasing level over time. The error bars indicate the error associated with mean for the cytokinin measurements for a given week. The SE of the difference in leaf active cytokinin content between weeks for each species $=1.11 \mathrm{pmol} \cdot \mathrm{g}^{-1} \mathrm{FW}$.

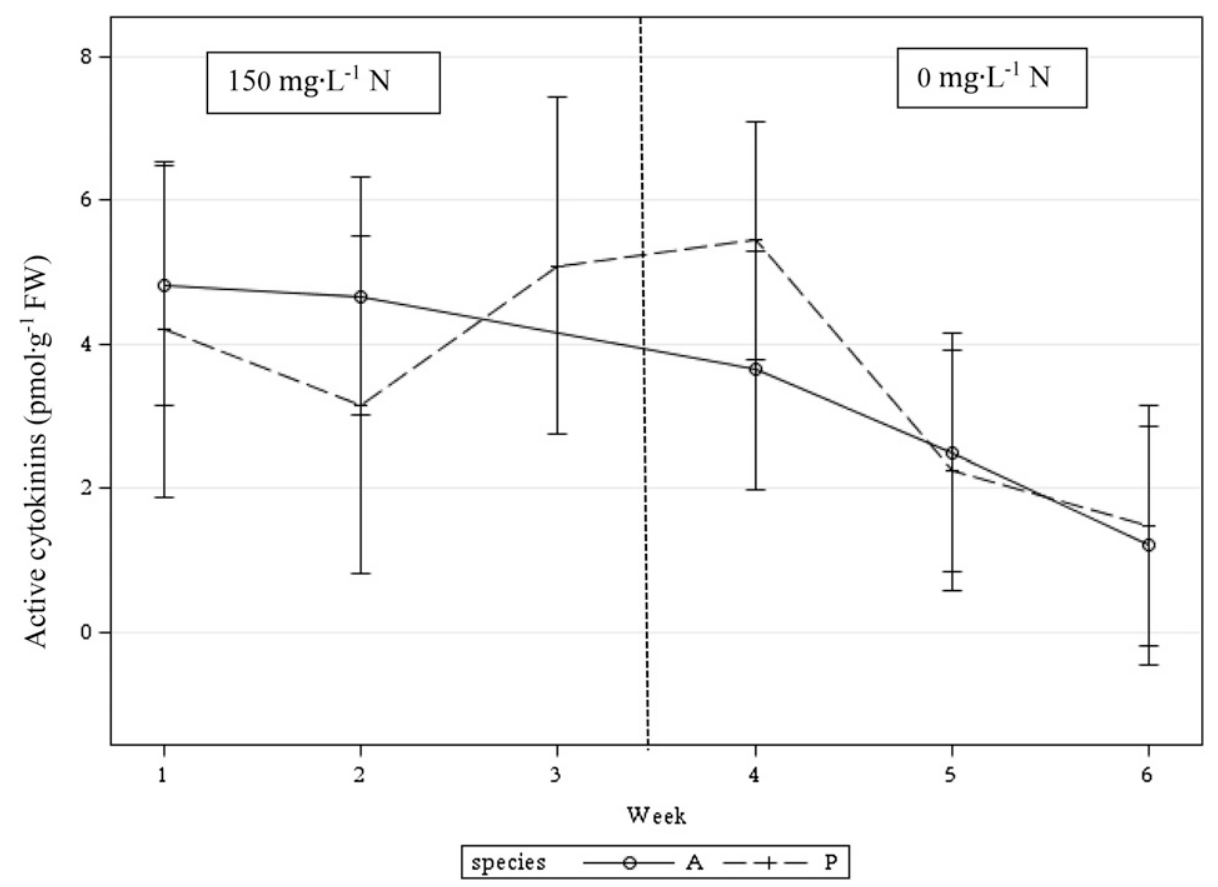

Fig. 6. Changes in the physiologically active cytokinin content in leaves of Plectranthus parviflorus (P) and Plectranthus ambiguus (A) in response to changes in $\mathrm{N}$ concentration over a 6-week period. The interaction of treatment by week was statistically significant indicating that both species reacted similarly to the presence or absence of $\mathrm{N}$ but how both species responded was different over the 6-week period in that, over time, once $\mathrm{N}$ was removed leaf active cytokinin content in $P$. ambiguus decreased. $P$. parviflorus leaf content showed a fluctuating response before week 6 where the final level of active cytokinin content was similar to that of $P$. ambiguus leaves. The error bars indicate the error associated with mean for the cytokinin measurements for a given week. The SE of the difference in leaf active cytokinin content between weeks for each species $=1.08 \mathrm{pmol} \cdot \mathrm{g}^{-1} \mathrm{FW}$. 
precursors were then determined in separate run as ribosides. Both fractions were separated by highperformance liquid chromatography (Ultimate 3000, Dionex; Thermo Fisher Scientific, Waltham, MA); and the cytokinins were quantified using a hybrid triple quadrupole/linear ion trap mass spectrometer (TSQ Quantum Ultra AM triple-quad high resolution mass spectrometer, Thermo Fisher Scientific) operated in selected reaction monitoring mode. Liquid chromatography-mass spectrometry analysis was performed as described by Dobrev et al. (2002) using an auto sampler with cooled sample stack (HTS-Pal; CTC Analytics, Zwingen, Switzerland), a quaternary high-pressure liquid chromatography pump (Rheos 2200; Flux Instruments, Basel, Switzerland), a column oven (Delta Chrom CTC 100; Watrex, Prague, Czech Republic), and a triple-quad high-resolution mass spectrometer (TSQ Quantum Ultra AM). Ternary gradient elution (water/acetonitrile/acetic acid) was used. The mass spectrometer (MS) was operated in the positive $\mathrm{MS} / \mathrm{MS}$ mode $(\mathrm{SRM}=$ single reaction monitoring) with monitoring of two to four transitions for each compound. The most intensive ion was used for quantification and the remainder for identity confirmation. Multilevel calibration graphs with $\left[{ }^{2} \mathrm{H}\right]$ labeled cytokinin internal standards were used for quantification. Detection limits of different cytokinins varied from 0.05 to $0.1 \mathrm{pmol} / \mathrm{sample}$. Two independent experiments were done. Each sample was injected at least twice.

STATISTICAL DESIGN AND ANALYSIS. For each experiment, the design was a split plot with repeated measures. The whole plot treatment factor was species. There were four whole plot units per bench. Two benches total. Each species was assigned to two of the four whole plot experimental units per bench. The split plot factor was the sequence of the four $\mathrm{N}$ treatments over two experimental periods (3 weeks per period; 6 weeks total). Technically, the split plot factor is a two-treatment

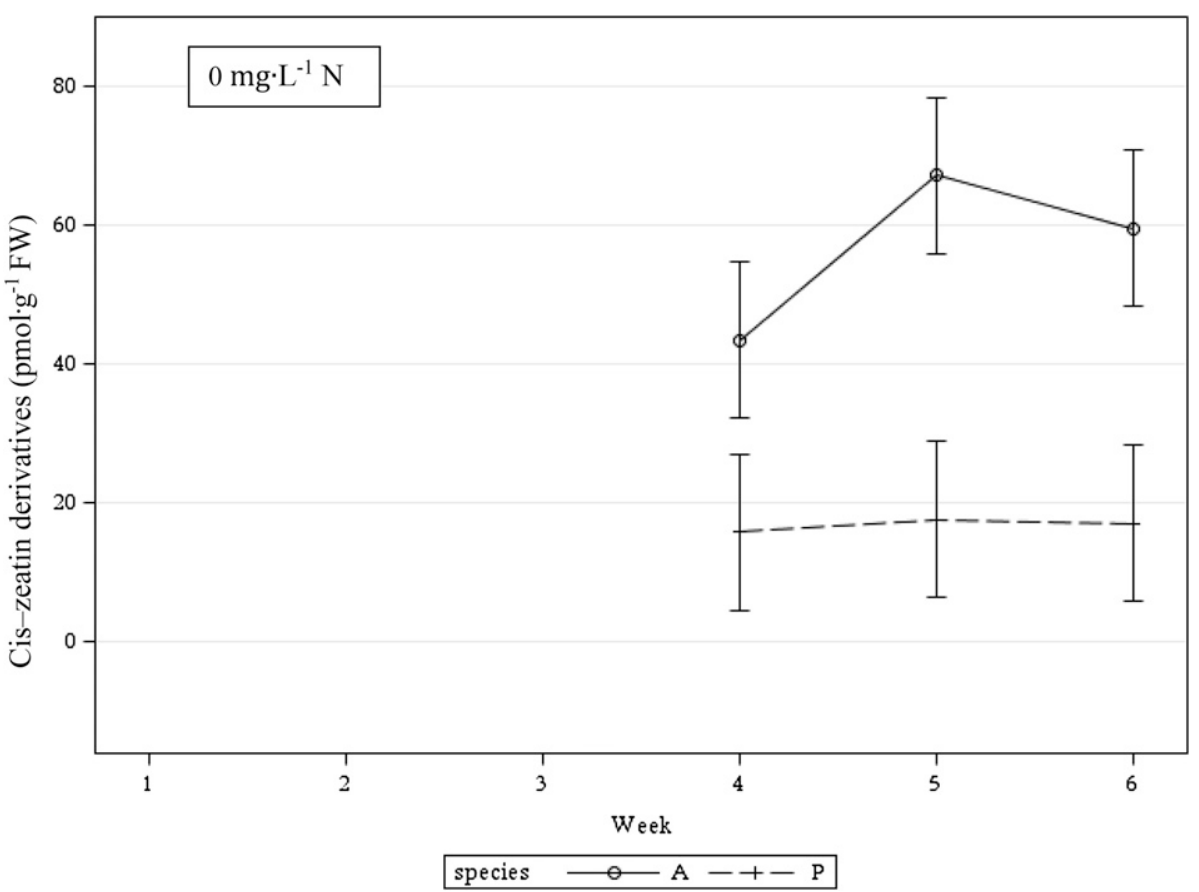

Fig. 7. Changes in cis-zeatin derivative content in leaves of Plectranthus parviflorus $(\mathrm{P})$ and Plectranthus ambiguus (A) in response to $\mathrm{N}$ deprivation over a 6-week period. The three-way interaction of species by treatment by week was statistically significant indicating that over the 6-week period of the study each species responded differently to the lack of $\mathrm{N}$ with leaves of $P$. parviflorus showing no change in cis-zeatin derivative content. The error bars indicate the error associated with mean for the cytokinin measurements for a given week. The SE of the difference in leaf $c i s$-zeatin derivative content between weeks for each species $=6.89 \mathrm{pmol} \cdot \mathrm{g}^{-1} \mathrm{FW}$.

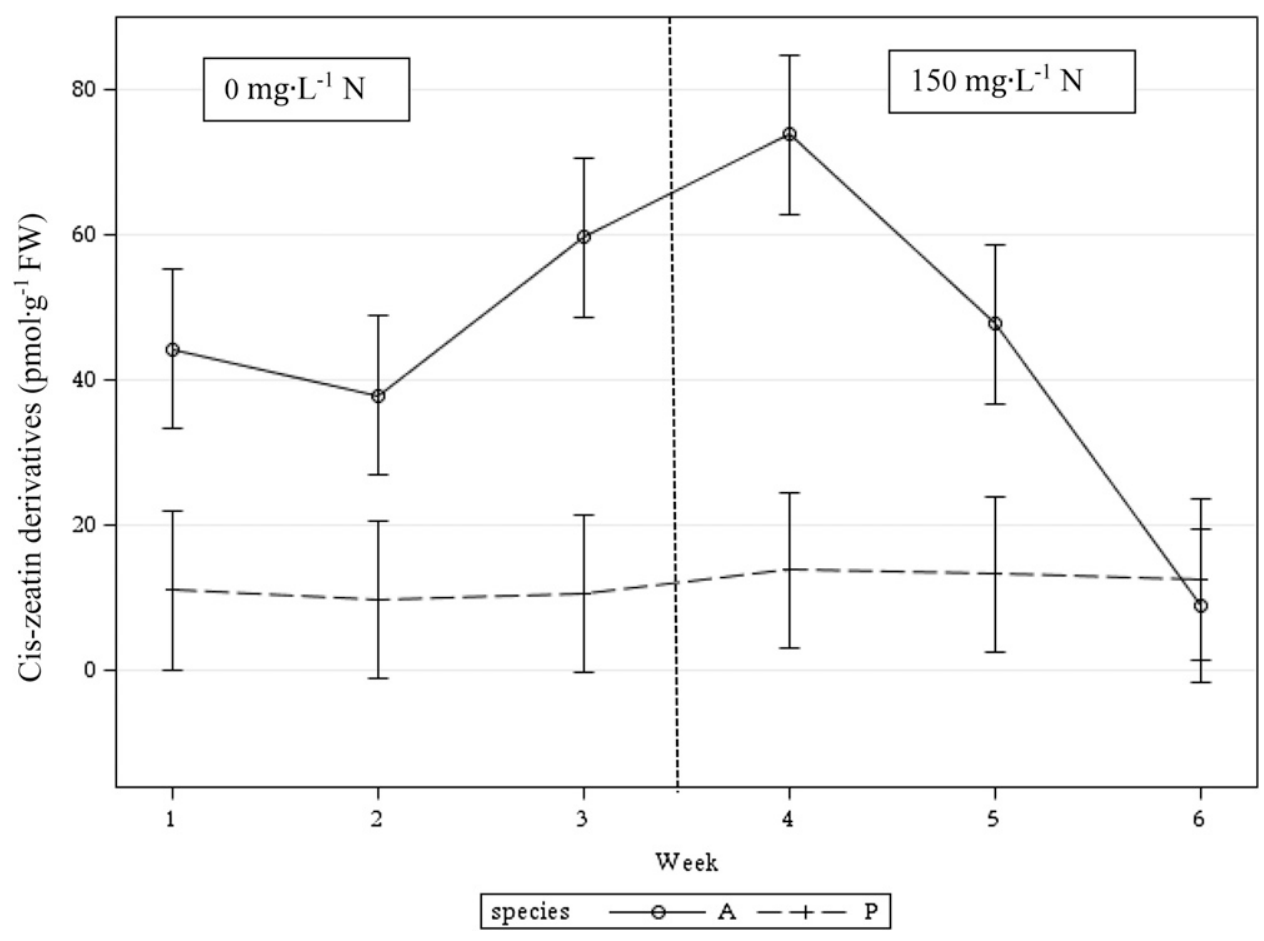

Fig. 8. Changes in cis-zeatin derivative content in leaves of Plectranthus parviflorus (P) and Plectranthus ambiguus (A) in response to changes in $\mathrm{N}$ concentration over a 6-week period. The three-way interaction of species by treatment by week was statistically significant indicating that over the 6-week period of the study each species responded differently to the presence or absence of $\mathrm{N}$ with the leaves of $P$. parviflorus showing no change in cis-zeatin derivative content. However, cis-zeatin derivative content fluctuated in P. ambiguus leaves particularly when $\mathrm{N}$ was introduced. The error bars indicate the error associated with mean for the cytokinin measurements for a given week. The SE of the difference in leaf cis-zeatin derivative content between weeks for each species $=6.61 \mathrm{pmol} \cdot \mathrm{g}^{-1} \mathrm{FW}$. 
two-period change-over design (Milliken and Johnson, 2009). There were four $\mathrm{N}$ treatment sequences: $0 \mathrm{~N}$ for both experimental periods (6 weeks total); $0 \mathrm{~N}$ in the first period ( 3 weeks) and then the switch to $150 \mathrm{mg} \cdot \mathrm{L}^{-1} \mathrm{~N}$ for the second period (3 weeks); $150 \mathrm{mg} \cdot \mathrm{L}^{-1} \mathrm{~N}$ in the first period (3 weeks) and then the switch to $0 \mathrm{~N}$ for the second period (3 weeks); and $150 \mathrm{mg} \cdot \mathrm{L}^{-1} \mathrm{~N}$ for both experimental periods ( 6 weeks). However, in any given whole plot unit, only three of the four $\mathrm{N}$ treatment sequences were included making it an incomplete block design. The chosen sequences optimized the precision of the measurements associated with the switch between 0 and full strength N. Thus some measurements were not taken. The split plot unit was the pot which contained one or two plants. Samples for chlorophyll and cytokinin determination were taken at multiple designated times with the emphasis on the regreening treatments $(0$ $\mathrm{N}-150 \mathrm{mg} \cdot \mathrm{L}^{-1} \mathrm{~N}$ and $150 \mathrm{mg} \cdot \mathrm{L}^{-1}$ $\mathrm{N}-0 \mathrm{~N}$ ) to ensure that the response profiles could be estimated over weeks $1-3$ for period 1 and weeks 4-6 for period 2. Data were analyzed using mixed model methods appropriate for split plot and repeated measure experiments (Littell et al., 2006). SAS ${ }^{\circledR}$ PROC GLIMMIX (SAS Institute, Cary, NC) was used to implement the analyses. The actual model (free of math notation) was: response $=$ variety + whole-plot error + sequence + sequence $\times$ variety + split-plot error + week + week $x$ variety + week $\times$ sequence + week $\times$ sequence $\times$ variety + repeatedmeasures error. It is necessary to use a mixed model procedure to adequately handle the multiple error terms, incomplete block and week features (as above) of these experiments. PROC GLIMMIX was used rather than PROC MIXED to take advantage of its advanced mean comparison features and plotting capabilities.

\section{Results}

The $\mathrm{N}$ concentration $\left(150 \mathrm{mg} \cdot \mathrm{L}^{-1}\right)$ as well as the experiment duration

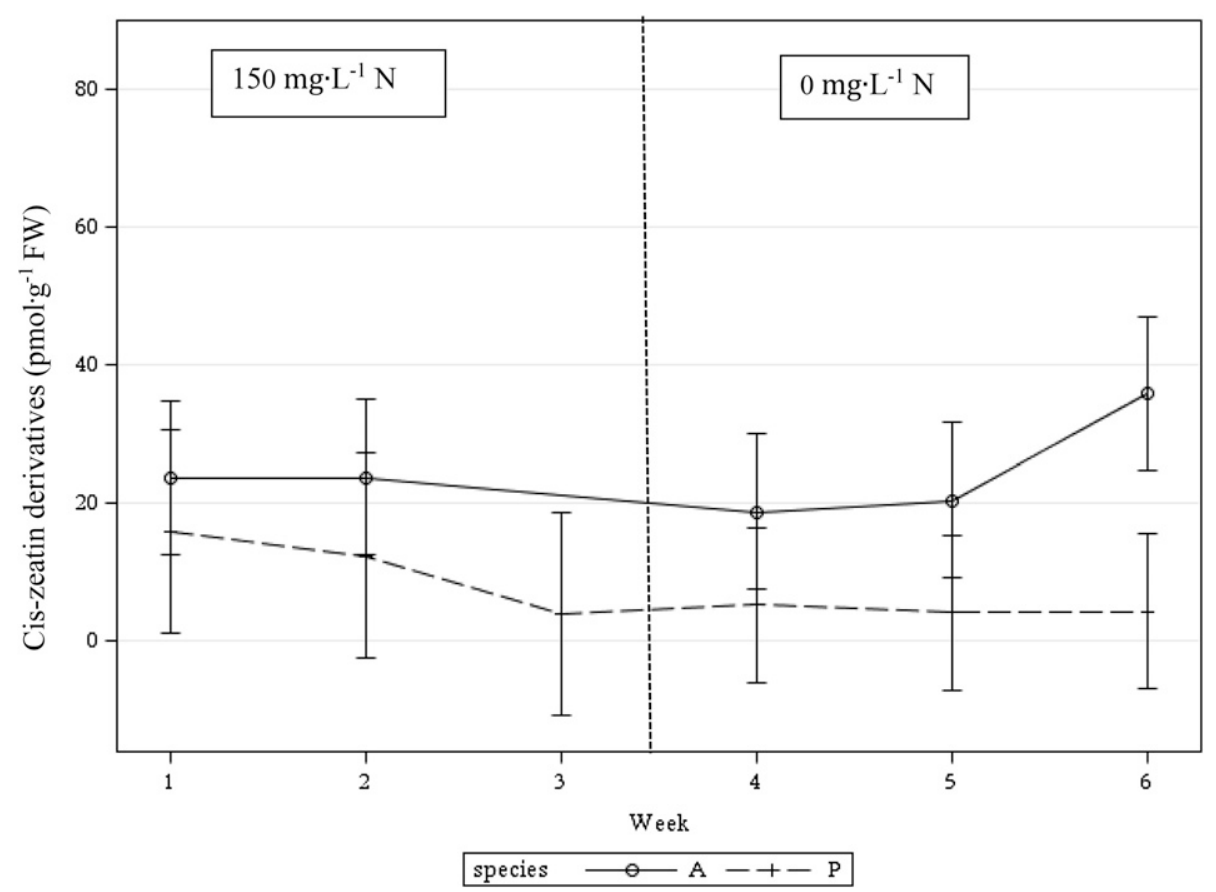

Fig. 9. Changes in cis-zeatin derivative content in leaves of Plectranthus parviflorus $(\mathrm{P})$ and Plectranthus ambiguus (A) in response to changes in $\mathrm{N}$ concentration over a 6-week period. The three-way interaction of species by treatment by week was statistically significant indicating that over the 6-week period of the study each species responded differently to the presence or absence of $\mathrm{N}$ in that once $\mathrm{N}$ was removed from the system $P$. ambiguus leaves showed an increase in active derivatives at week 6. Cis-zeatin derivative content in leaves of $P$. parviflorus decreased when $\mathrm{N}$ was present and then did not respond further when $\mathrm{N}$ was removed from the system. The error bars indicate the error associated with mean for the cytokinin measurements for a given week. The SE of the difference in leaf $c i s$-zeatin derivative content between weeks for each species $=6.97 \mathrm{pmol} \cdot \mathrm{g}^{-1} \mathrm{FW}$.

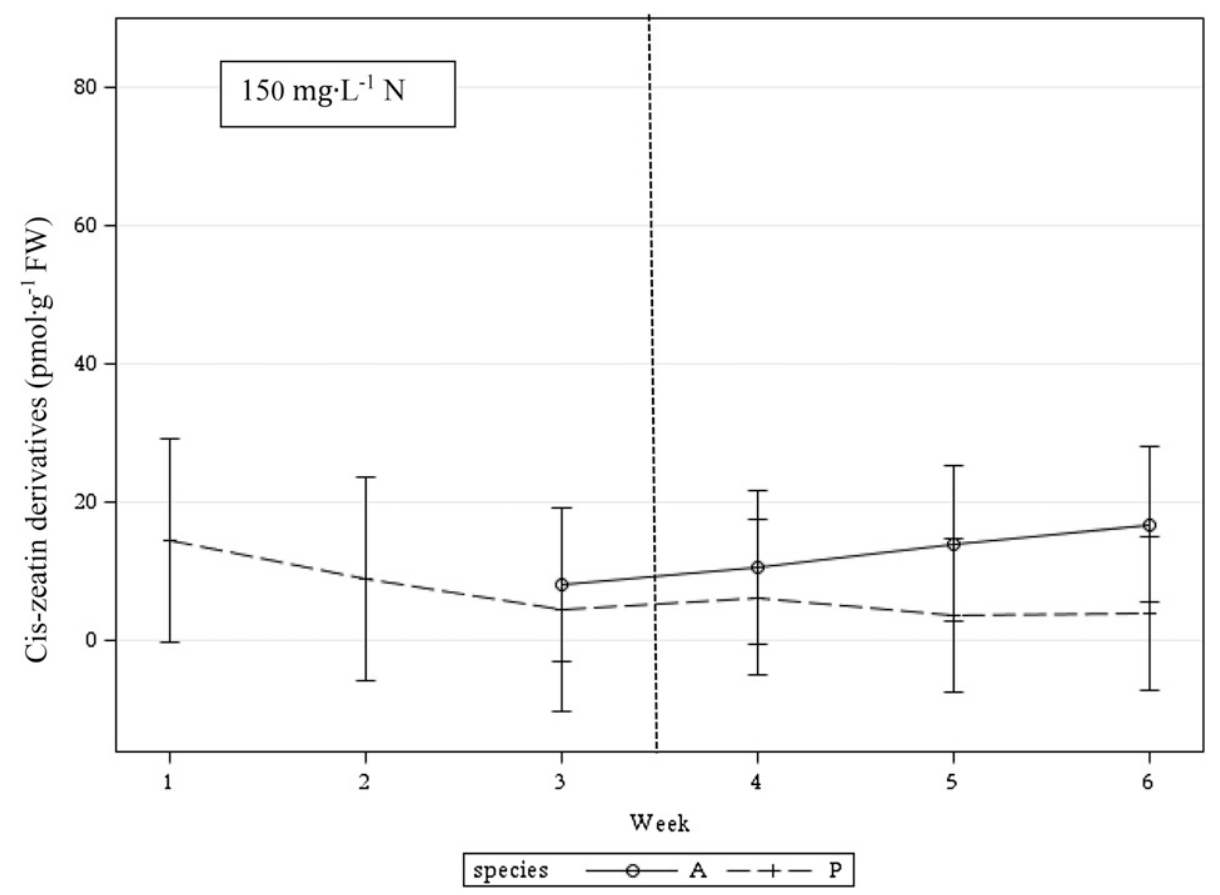

Fig. 10. Changes in cis-zeatin derivative content in leaves of Plectranthus parviflorus $(\mathrm{P})$ and Plectranthus ambiguus $(\mathrm{A})$ in response to a set $\mathrm{N}$ concentration over a 6-week period. The three-way interaction of species by treatment by week was statistically significant indicating that over the 6-week period of the study each species responded differently to the presence of $\mathrm{N}$ with leaves of $P$. ambiguus showing an increase in cis-zeatin derivative content. Cis-zeatin derivative content in leaves of $P$. parviflorus decreased when $\mathrm{N}$ was present and then stabilized. The error bars indicate the error associated with mean for the cytokinin measurements for a given week. The SE of the difference in leaf cis-zeatin content between weeks for each species $=7.02 \mathrm{pmol} \cdot \mathrm{g}^{-1} \mathrm{FW}$. 
$(3+3$ weeks $)$ were optimized in preliminary experiments, to ensure complete regreening of $P$. parviflorus plants. Cuttings of both Plectranthus species were rooted in vermiculite with no nutrients supplied and appeared yellowish and slightly deficient when placed in the hydroponic solutions. Once in solution, they received either all nutrients or all except of N. Full N supplementation $\left(150 \mathrm{mg} \cdot \mathrm{L}^{-1} \mathrm{~N}\right)$ ensured regreening of $P$. parviflorus plants within 3 weeks. The $\mathrm{N}$ concentration of plants that received no nitrogen during the experiments were $0.02 \% \pm 0.01 \%$, whereas plants receiving $150 \mathrm{mg} \cdot \mathrm{L}^{-1} \mathrm{~N}$ ranged from $5.98 \%$ to $7.26 \%$.

Chlorophyll Concentration. Chlorophyll content of fully expanded leaves from the second pair down from the terminal whorl was followed in the absence of $\mathrm{N}$ or after its supplementation. Both species showed a decrease in chlorophyll concentration within 1 week of $\mathrm{N}$ deficiency. This trend continued in both species as long as $\mathrm{N}$ was withheld (concentrations at 6 weeks $\approx 0.3$ and $0.2 \mathrm{mg} \cdot \mathrm{g}^{-1} \mathrm{FW}$, respectively) (data not shown). Statistical analysis revealed that the three-way interaction of species by treatment by week was significant indicating that each species responded differently to the presence or absence of $\mathrm{N}$ over the 6-week period. Initially, $P$. ambiguus plants contained about double the basal concentration of chlorophyll than P. parviflorus, despite both having yellow-green leaves after the rooting period. After 3 weeks of $\mathrm{N}$ deficiency, abscission of lower and later on of middle leaves was observed in P. ambiguus plants. When $\mathrm{N}$ was added to the solution after sampling at week 3 [0-150 $\mathrm{mg} \cdot \mathrm{L}^{-1} \mathrm{~N}$ treatment (Fig. 1)], chlorophyll concentration of $P$. ambiguus plants started increasing, but within 3 weeks did not regain the initial concentration level. Three-week $\mathrm{N}$ supplementation caused only a little change in chlorophyll concentrations in $P$. parviflorus plants. This is despite the fact that leaves appeared visually green. This was validated by scoring $137 \mathrm{~A}$ green using the RHS Color Chart.

When $P$. ambiguus received $150 \mathrm{mg} \cdot \mathrm{L}^{-1} \mathrm{~N}$ for the first 3 weeks

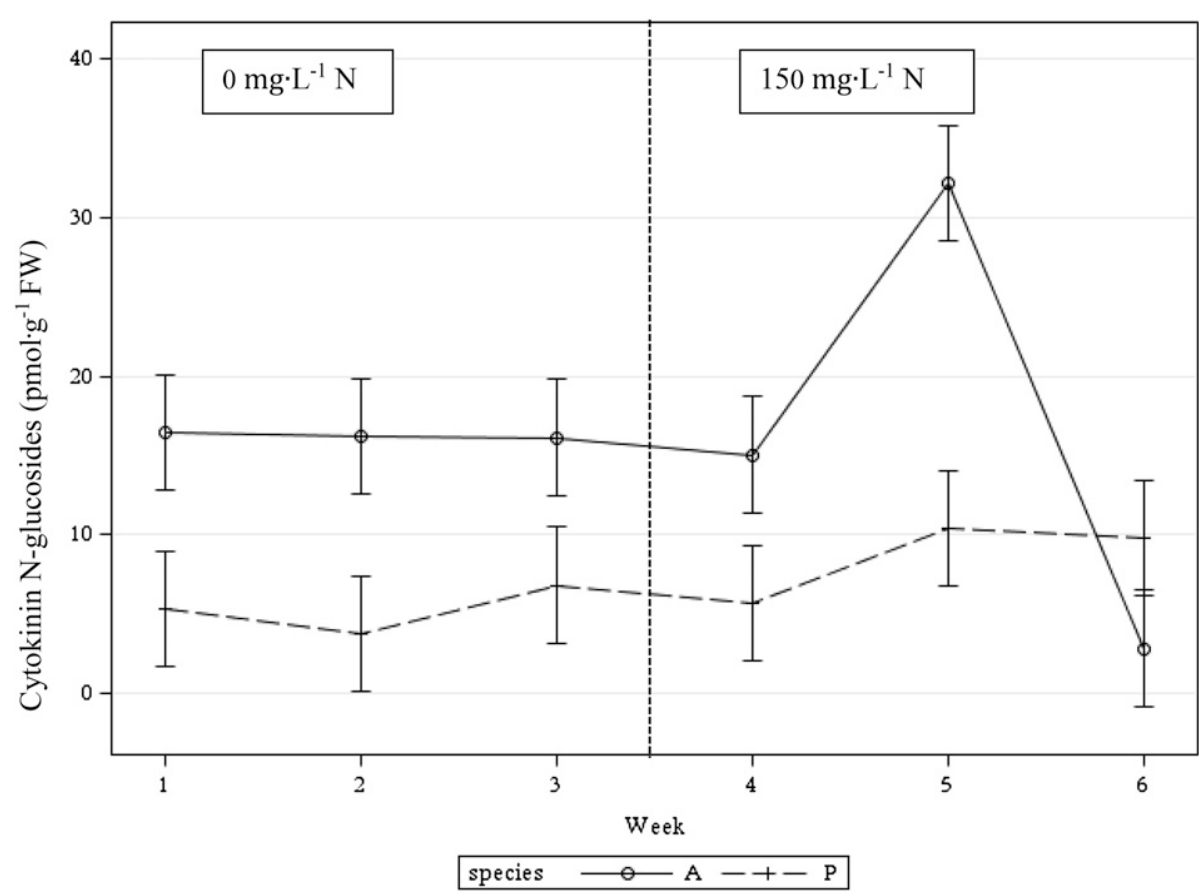

Fig. 11. Changes in the cytokinin N-glucoside content in leaves of Plectranthus parviflorus (P) and Plectranthus ambiguus (A) in response to changes in $\mathrm{N}$ concentration over a 6-week period. The three-way interaction of species by treatment by week was statistically significant indicating that over the 6-week period each species responded differently to the presence or absence of $\mathrm{N}$ in that $P$. ambiguus leaves showed a dramatic increase $\mathrm{N}$-glucoside content after 2 weeks of $\mathrm{N}$ supplementation. Leaves of $P$. parviflorus showed only a slight increase in $\mathrm{N}$-glucoside content once $\mathrm{N}$ was added back to the system. The error bars indicate the error associated with mean for the cytokinin measurements for a given week. The SE of the difference in leaf cytokinin N-glucoside content between weeks for each species $=2.44 \mathrm{pmol} \cdot \mathrm{g}^{-1} \mathrm{FW}$.

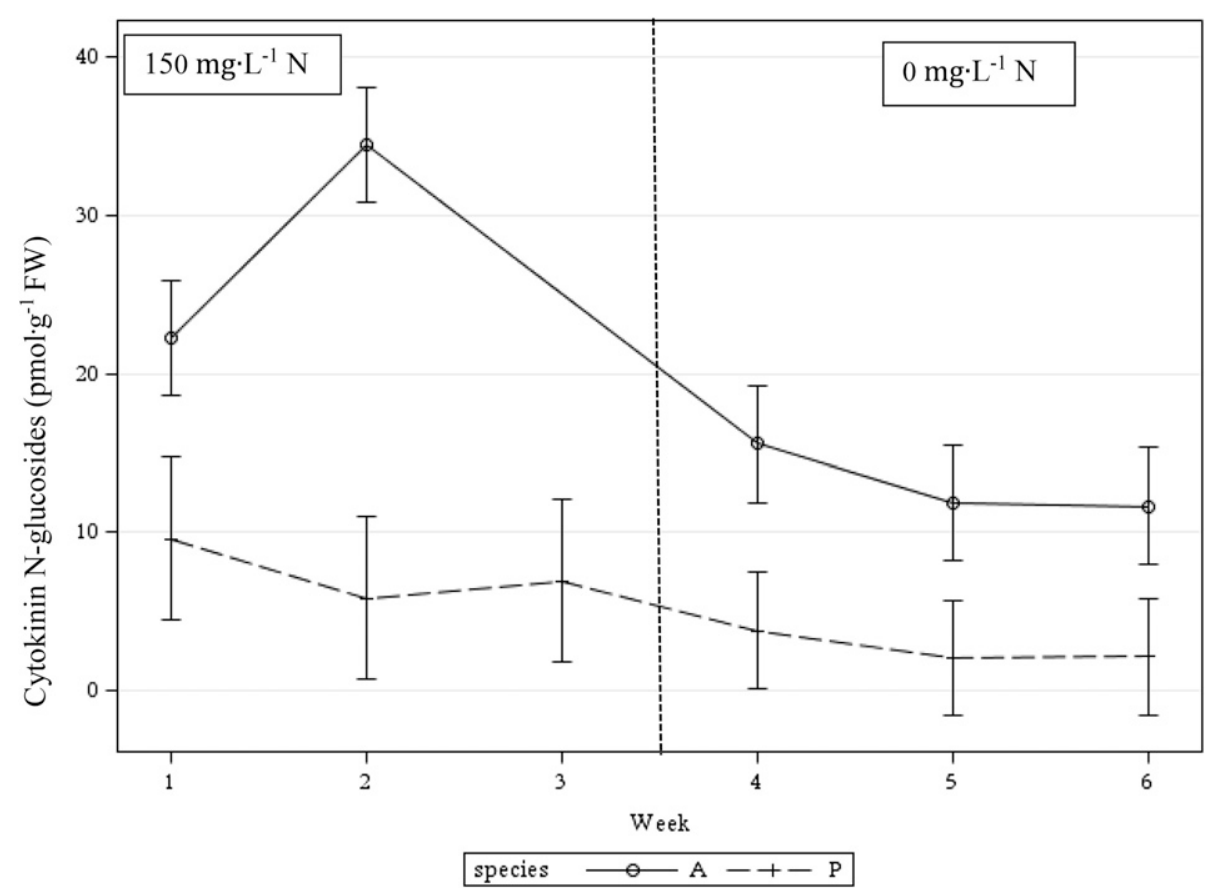

Fig. 12. Changes in the cytokinin N-glucoside content in leaves of Plectranthus parviflorus $(\mathrm{P})$ and Plectranthus ambiguus (A) in response to changes in $\mathrm{N}$ concentration over a 6-week period. The three-way interaction of species by treatment by week was statistically significant indicating that over the 6-week period each species responded differently to the presence or absence of $\mathrm{N}$. While both species showed a decrease in $\mathrm{N}$-glucoside content, the decrease was greater in leaves of $P$. ambiguus. The error bars indicate the error associated with mean for the cytokinin measurements for a given week. The SE of the difference in leaf cytokinin N-glucoside content between weeks for each species $=2.41 \mathrm{pmol} \cdot \mathrm{g}^{-1} \mathrm{FW}$. 
(Fig. 2), chlorophyll concentrations were stable. After $\mathrm{N}$ removal at week 3, chlorophyll concentrations of $P$. ambiguus leaves remained high until week 4 and then started decreasing. However, $P$. parviflorus plants showed little upregulation during 3 -week $\mathrm{N}$ supplementation. When $\mathrm{N}$ was removed, only a mild response was observed and it took 3 weeks for chlorophyll concentration to drop. When both species received $150 \mathrm{mg} \cdot \mathrm{L}^{-1} \mathrm{~N}$ for the entire 6 weeks, chlorophyll concentration in leaves of $P$. ambiguus increased from 1.5 to $2.1 \mathrm{mg} \cdot \mathrm{g}^{-1} \mathrm{FW}$. Plectranthus parviflorus leaves showed chlorophyll elevation from 0.8 to $1.3 \mathrm{mg} \cdot \mathrm{g}^{-1} \mathrm{FW}$, mainly in the last 2 weeks (data not shown).

CYTOKININ BIOSYNTHETIC PRECURSORS (CYTOKININ PHOSPHATES). The relationship between $\mathrm{N}$ supplementation and endogenous cytokinin content was compared in Plectranthus species exhibiting differential response to the nutrient limitation. The initial $\mathrm{N}$ deficiency was associated with low levels of cytokinin phosphates (includes trans-zeatin riboside phosphate, isopentenyladenosine phosphate, and dihydrozeatin riboside phosphate), consistently in both species (Fig. 3). When $\mathrm{N}$ was introduced after 3 weeks of $\mathrm{N}$ deficiency, levels of cytokinin precursors were enhanced, to a higher extent, in $P$. ambiguus (Fig. 3). The statistical analysis (significant three-way interaction of species by $\mathrm{N}$ treatment by week) revealed different responses between the tested species over the 6-week period due to the presence or absence of $\mathrm{N}$. Nitrogen supplementation for the first 3 weeks coincided with relatively high content of cytokinin phosphates (Fig. 4). Upon withdrawal of $\mathrm{N}$ after 3 weeks of full nutrition, there was a significant decrease in the cytokinin phosphates in leaves of both $P$. ambiguus and $P$. parviflorus. When no nitrogen was provided for 6 weeks, cytokinin phosphates were very low [values similar to week 6 in Fig. 4 (data not shown)]. When plants received full strength $\mathrm{N}$ for 6 weeks, cytokinin precursors for both species peaked at 6-7 $\mathrm{pmol} \cdot \mathrm{g}^{-1} \mathrm{FW}$ (data not shown).

ACtive CYTOKinins. When nutrient solution without $\mathrm{N}$ was supplied to plants for 6 weeks, the concentration of the active cytokinins (trans-zeatin, dihydrozeatin, isopentenyladenine, and their ribosides) in $P$. parviflorus and $P$. ambiguus declined (data not shown). Simultaneously, leaf yellowing and growth cessation were observed for $P$. parviflorus, whereas $P$. ambiguus began to lose leaves, starting from the bottom. Statistical analysis (interaction of $\mathrm{N}$ treatment by week) indicated that active cytokinins in both species responded to the presence or absence of $\mathrm{N}$ in a similar way in that they decreased in the absence of $\mathrm{N}$ and increased once $\mathrm{N}$ was supplied. However, different patterns of response by each species were observed over the 6-week period. When $\mathrm{N}$ was supplied after a 3-week $\mathrm{N}$ deficiency, $P$. parviflorus plants responded by an elevation of the active cytokinin concentrations (Fig. 5). Response of $P$. ambiguus plants was similar, but milder. When plants of $P$. ambiguus received $150 \mathrm{mg} \cdot \mathrm{L}^{-1} \mathrm{~N}$ during the first 3 weeks of the experiment, the level of active cytokinins in leaves was significantly higher than in the absence of $\mathrm{N}$ (Fig. 6). Once $\mathrm{N}$ was removed from the solution, the concentration of active cytokinins fell as $\mathrm{N}$ deficiency increased. The response of $P$. parviflorus plants was delayed by 1 week. However, by week 5 the levels of active cytokinins were the same for both species.

Cis-Zeatin derivatives. As cis-zeatin and its riboside are cytokinins often associated with stress responses, cis-zeatintype cytokinins were evaluated separately from the other cytokinins. Originally, both cis-zeatin and cis-zeatin riboside were considered inactive products of transfer RNA degradation. However, when cytokinin receptors were identified and their affinity to different cytokinin bases and ribosides was compared, they started to be considered to be active cytokinins. Statistical analysis (significant three-way interaction of species by $\mathrm{N}$ treatment by week) showed significant differences in the cis-zeatin-type pool between the tested species. Overall, the levels of cis-zeatin and its riboside were lower in $P$. parviflorus than in P. ambiguus. In the latter, the levels of the most abundant cis-zeatin derivatives (i.e., cis-zeatin O-and $\mathrm{N}$-glucosides) were comparable to the content of trans-zeatin-, isopentenyladenine-, and dihydrozeatin-type-O and N-glucosides. Nitrogen addition generally did not affect the concentration of $c i s$-zeatin derivatives (9.8-15.9 pmol. $\mathrm{g}^{-1} \mathrm{FW}$ ) in P. parviflorus leaves (Figs. 7-10). Their levels were maintained whether $\mathrm{N}$ was present or not. However, the cis-zeatin derivatives represented predominant

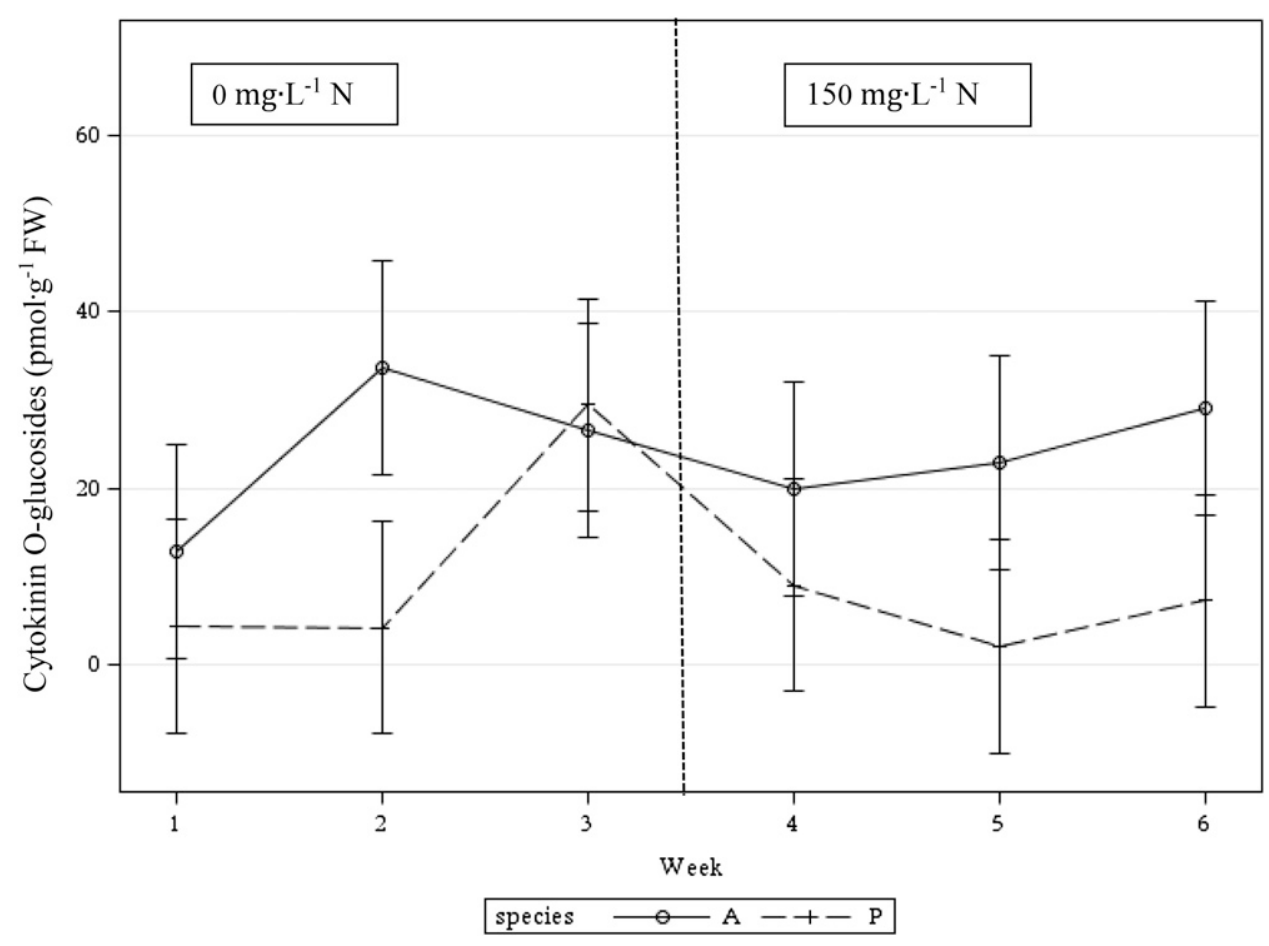

Fig. 13. Changes in the cytokinin O-glucoside content in leaves of Plectranthus parviflorus $(\mathrm{P})$ and Plectranthus ambiguus (A) in response to changes in $\mathrm{N}$ concentration over a 6 -week period. The three-way interaction of species by treatment by week was statistically significant indicating that over the 6-week period each species responded differently to the presence or absence of $\mathrm{N}$. Under $\mathrm{N}$ deprivation, both species showed a peak in O-glucoside leaf content. However, on reintroduction of $\mathrm{N}$, only leaves of $P$. ambiguus showed a recovery to peak level. The error bars indicate the error associated with mean for the cytokinin measurements for a given week. The SE of the difference in leaf cytokinin O-glucoside content between weeks for each species $=2.41 \mathrm{pmol} \cdot \mathrm{g}^{-1} \mathrm{FW}$. 
cytokinin forms in $P$. ambiguus plants, showing the highest concentrations at weeks 5 and 6 in case of the 6-week $\mathrm{N}$ deficiency [43.5-59.6 pmol.g ${ }^{-1} \mathrm{FW}$ (Fig. 7)]. When P. ambiguus plants received no $\mathrm{N}$ for the first 3 weeks, the concentration cis-zeatin derivatives rose and reached maximum at week 4, then it dropped precipitously by week 6 due to a consistent $N$ supply (Fig. 8). Leaves of $P$. ambiguus plants that received $150 \mathrm{mg} \cdot \mathrm{L}^{-1} \mathrm{~N}$ for all 6 weeks had 4-15 pmol. $\mathrm{g}^{-1} \mathrm{FW}$ of cis-zeatin derivatives (Fig. 10); i.e., about one-third of the concentration of $\mathrm{N}$ deficient plants. This difference was mirrored in the 150-0 $\mathrm{N}$ treatment where low levels were maintained at $\mathrm{N}$ presence, but after 3-week $\mathrm{N}$ deficiency, ciszeatin derivative concentration started increasing (Fig. 9).

Cytokinin N-GLucosides. Statistical analysis (the three-way interaction of species by $\mathrm{N}$ treatment by week) indicated significant differences in cytokinin N-glucosides between the tested species over the 6-week period due to the presence or absence of $\mathrm{N}$. When both species received no $\mathrm{N}$ but all the other elements, the levels of cytokinin deactivation products (N-glucosides of trans-zeatin, dihydrozeatin, and isopentenyladenine) were not significantly changed in either species for weeks 1-3 [7.4-13.7 pmol. ${ }^{-1}$ FW (Fig. 11)]. Addition of $\mathrm{N}$ after 3 weeks of deprivation resulted in upregulation of cytokinin $\mathrm{N}$ glucosides in both species. Plectranthus ambiguus responded with a dramatic increase at week 5, doubling the cytokinin N-glucosides concentration. Plectranthus parviflorus plants showed a similar profile, but cytokinin N-glucoside increase at week 5 was only mild. However, it did coincide with the beginning of leaf regreening. However, by week 6 both species had concentrations similar to those observed in plants grown for 6 weeks without $\mathrm{N}$ (data not shown). When $\mathrm{N}$ was supplied during the first 3 weeks and then removed, cytokinin $\mathrm{N}$ glucosides decreased in both species indicating downregulation of cytokinin N-glucosylation, together with the suppression of cytokinin biosynthesis, particularly in $P$. ambiguus plants (Fig. 12). When N was supplied for the whole period, a transient increase of cytokinin $\mathrm{N}$-glucoside content was found in $P$. ambiguus plants after 2 weeks (data not shown).

Cytokinin O-glucosides. Statistical analysis (significant interaction of species by week) indicated significant differences in dynamics of cytokinin O-glucosides (includes trans-zeatin O-glucoside, trans-zeatin riboside O-glucoside, dihydrozeatin O-glucoside, and dihydrozeatin O-riboside glucoside) over the 6-week period between the species. Both species showed a peak in cytokinin O-glucosides: $P$. ambiguus after 2 weeks and $P$. parviflorus after 3 weeks (Fig. 13). On reintroduction of $\mathrm{N}$, initially, both species showed a decrease in cytokinin O-glucosides. However, after 3 weeks, $P$. ambiguus leaves showed a recovery of cytokinin O-glucoside content to peak level.

When $\mathrm{N}$ deficiency was induced after full $\mathrm{N}$ treatment, levels of cytokinin O-glucosides decreased between weeks 2 and 4 (Fig. 14). Decline of cytokinin O-glucosides, starting at week 2, was found in leaves of $P$. ambiguus. Prolonged $N$ limitation resulted in a continued decrease of cytokinin O-glucosides in both species. For $P$. ambiguus, the $150 \mathrm{mg} \cdot \mathrm{L}^{-1} \mathrm{~N}$ treatment resulted in strong upregulation of cytokinin O-glucoside concentration, especially at the beginning of the experiment (week 2), the response being stronger than in $P$. parviflorus. Constant $\mathrm{N}$ treatment was associated with low cytokinin O-glucoside content [10-30 $\mathrm{pmol} \cdot \mathrm{g}^{-1} \mathrm{FW}$ (data not shown)] in both species.

\section{Discussion}

Different plant species or even individual genotypes may adopt a different strategy to adjust to $\mathrm{N}$ deficiency. We compared two Plectranthus species, $P$. parviflorus and $P$. ambiguus, which differ substantially in their response to $\mathrm{N}$ limitation. The leaves of the former species gradually yellow during the nutrient stress but are retained, while the latter one responds by abscission of lower leaves (Borman et al., 2013). Preliminary experiments on $P$. parviflorus demonstrated that this species can be exposed repeatedly to $\mathrm{N}$ deficiency conditions and repeatedly regreen on reintroduction of $\mathrm{N}$ without leaf senescence and loss (data not shown).

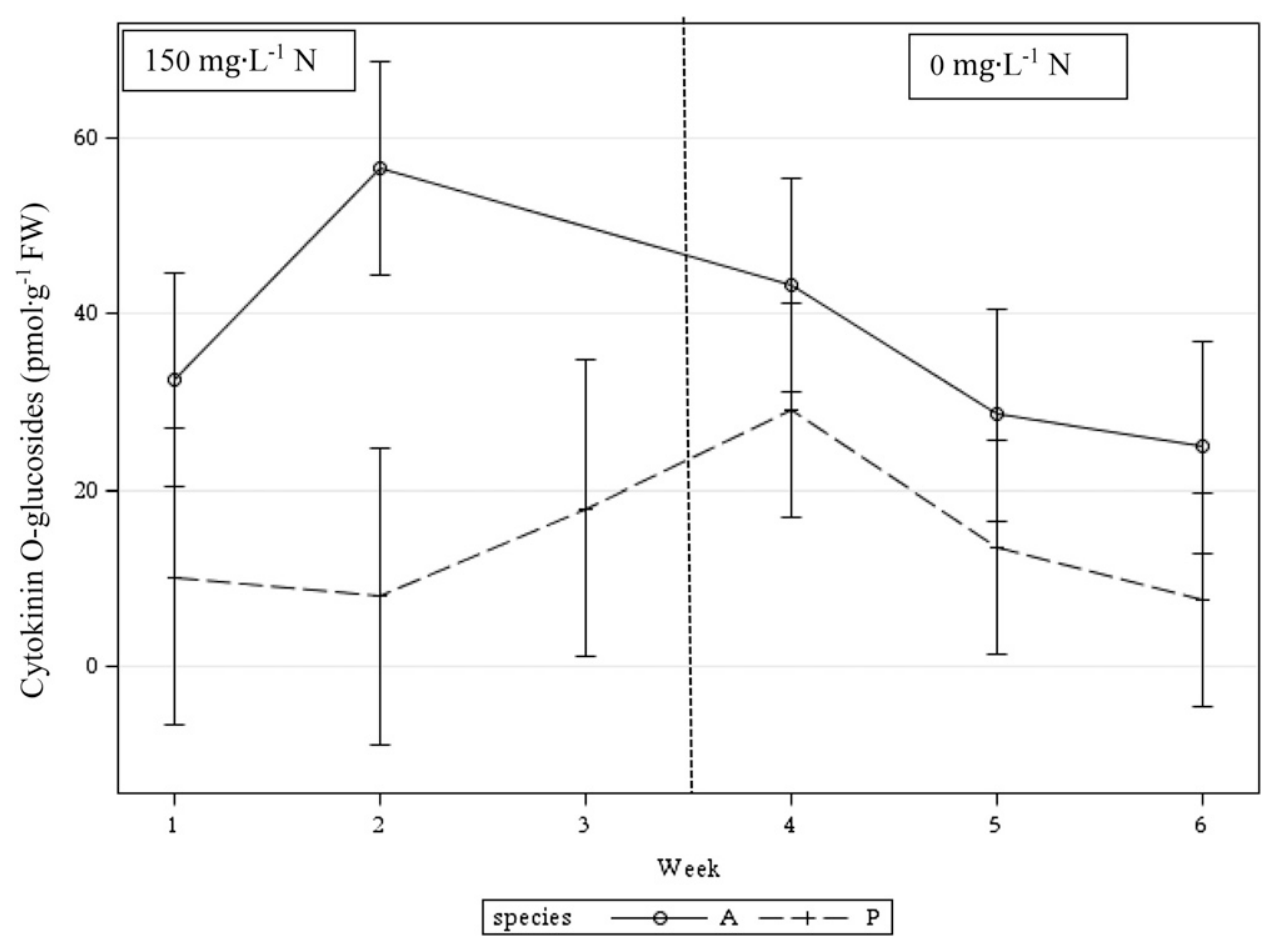

Fig. 14. Changes in the cytokinin O-glucoside content in leaves of Plectranthus parviflorus (P) and Plectranthus ambiguus (A) in response to changes in $\mathrm{N}$ concentration over a 6-week period. The interaction of species by week was statistically significant indicating that during the 6-week period each species responded differently regardless of $\mathrm{N}$ presence or absence. $P$. ambiguus leaf $\mathrm{O}$-glucoside content showed a similar response to $\mathrm{N}$ presence and removal as $\mathrm{N}$-glucoside content. However, $P$. parviflorus leaves showed an increase in O-glucosides when $\mathrm{N}$ was present and then a decrease after 2 weeks without $\mathrm{N}$. The error bars indicate the error associated with mean for the cytokinin measurements for a given week. The SE of the difference in leaf cytokinin O-glucoside content between weeks for each species $=2.61 \mathrm{pmol} \cdot \mathrm{g}^{-1} \mathrm{FW}$. 
The ability of plants to sense $\mathrm{N}$ and to regulate its uptake is a crucial part of plant adaptation to variable environmental conditions, including nutrient availability (Argueso et al., 2009). The role of cytokinins in these processes has been established (Kiba et al., 2011) and cytokinins were reported as long-distance signals which coordinate $\mathrm{N}$ demand and acquisition (Ruffel et al., 2011). Our results confirmed close $\mathrm{N}-$ cytokinin relationship. Nitrogen strongly affected cytokinin biosynthesis in both Plectranthus species, as indicated by the positive correlation between the presence of $\mathrm{N}$ in the medium and the levels of cytokinin precursors (cytokinin phosphates). This finding is in accordance with the stimulatory effect of nitrate on the expression of genes for cytokinin biosynthetic enzymes IPT3 or IPT5 (Takei et al., 2001a) as well as of CYP735A2 (Wang et al., 2004) in arabidopsis (Arabidopsis thaliana).

Low levels of cytokinin phosphates, induced by $\mathrm{N}$ deficiency, corresponded well to the low levels of active cytokinins in both species. Simultaneously, cytokinin deactivation was suppressed, as indicated by the low levels of cytokinin $\mathrm{O}$ - and $\mathrm{N}$-glucosides, which suggests tendency to maintain the levels of active cytokinins as high as possible, even under conditions of their suppressed biosynthesis. Conversely, $\mathrm{N}$ supplementation had a rapid positive effect on active cytokinin levels in both species. High increase in active cytokinin levels was followed by transient elevation of cytokinin O- and N-glucosylation, probably to establish cytokinin homeostasis. This positive effect of $\mathrm{N}$ on active cytokinin concentrations in Plectranthus species is in accordance with reports on number of other species; e.g., sunflower [Helianthus annnus (Salama and Wareing, 1979)], barley [Hordeum vulgare cv. Golf (Samuelson and Larsson, 1993)], maize [Zea mays (Takei et al., 2001b)], or Festulolium [cv. Felina (Pavliková et al., 2012)].

In spite of generally similar response to $\mathrm{N}$ deficiency/ supplementation, $P$. parviflorus differed by accumulation of huge starch grains under control conditions (continual $\left.150 \mathrm{mg} \cdot \mathrm{L}^{-1} \mathrm{~N}\right)$. This starch supply was slowly hydrolyzed when the plants were stressed by the lack of $\mathrm{N}$ (Korus et al., 2010). The starch hydrolysis resulted in the release of reducing sugars, which may serve as a sugar source/signal to maintain leaf integrity and prevent leaf abscission to diminish/tolerate the $\mathrm{N}$ stress. In contrast, $P$. ambiguus reacts to $\mathrm{N}$ stress by abscission of the lower leaves. It is interesting that $\mathrm{N}$ deficiency in the leaf abscising $P$. ambiguus is associated with an elevation of cis-zeatin type cytokinin content, the form of cytokinins reported to play a role during stress conditions (Gajdosova et al., 2011). The cis-zeatin and its riboside exhibit much lower physiological activity than trans-zeatin (Gajdosova et al., 2011), interacting with only a subgroup of cytokinin receptors (Spichal et al., 2004). This elevation of cis-zeatin in the upper leaves under these $\mathrm{N}$ stress conditions may enable the cytokinins to increase the sink strength of the upper leaves and influence the abscission of lower leaves and remobilization of nutrients from the abscising leaves to the upper leaves. In $P$. parviflorus, the regreening plant, $\mathrm{N}$ deprivation did not affect the concentration of cis-zeatin derivatives. Thus, another mechanism is involved.

As cytokinins have a direct link to chlorophyll concentration, stimulating its biosynthesis in dark, as well as slowing down its degradation during senescence, we compared the $\mathrm{N}$ response in $P$. parviflorus and $P$. ambiguus at the level of chlorophyll content as well. The chlorophyll concentration followed the cytokinin dynamics in both plant species. However, the leaf regreening plant, $P$. parviflorus, exhibited a delay in chlorophyll downregulation by 1 week in comparison with $P$. ambiguus. The response was even slower in the case of $\mathrm{N}$ resupplementation. This may be in part because the range of chlorophyll concentration in the leaf regreening plant, $P$. parviflorus, was generally lower than in $P$. ambiguus even though the plants visually appeared green.

In conclusion, the link between cytokinins and nitrogen metabolism has long been established in other plants. In this research, there is a unique situation in that two species differ in their response to nitrogen loss in that one will shed lower leaves while the other does not. This phenotypic stress response has been associated with cis-zeatin-type cytokinin accumulation in $P$. ambiguus, the leaf abscising species, but not in $P$. parviflorus. While the underlying mechanism that allows $P$. parviflorus to retain its leaves during $\mathrm{N}$ deprivation and eventual regreening does not appear to be related to cis-zeatin-type cytokinin content, it may involve plant survival mechanisms such as starch hydrolysis.

\section{Literature Cited}

Argueso, C.T., F.J. Ferreira, and J.J. Kieber. 2009. Environmental perception avenues: The interaction of cytokinin and environmental response pathways. Plant Cell Environ. 32:1147-1160.

Arnon, D.I. 1949. Copper enzymes in isolated chloroplasts, polyphenoloxidase in Beta vulgaris. Plant Physiol. 24:1-15.

Borman, C., E.T. Paparozzi, and M.E. Conley. 2013. The ability of Plectranthus parviflorus and P. ambiguus to regreen after micronutrient deficiency. HortScience 48:S391. (abstr.).

Dobrev, P.I. and M. Kaminek. 2002. Fast and efficient separation of cytokinins from auxin and abscisic acid and their purification using mixed-mode solid-phase extraction. J. Chromatography 950: 21-29.

Dobrev, P., V. Motyka, A. Gaudinova, J. Malbeck, A. Travnickova, M. Kaminek, and R. Vankova. 2002. Transient accumulation of cis- and trans-zeatin type cytokinins and its relation to cytokinin oxidase activity during cell cycle of synchronized tobacco BY-2 cells. Plant Physiol. Biochem. 40:333-337.

Gajdosova, S., L. Spichal, M. Kaminek, K. Hoyerova, O. Novak, P.I. Dobrev, P. Galuszka, P. Klima, A. Gaudinova, E. Zizkova, J. Hanus, M. Dancak, B. Travnicek, B. Pesek, M. Krupicka, R. Vankova, and M.M.V. Strnad. 2011. Distribution, biological activities, metabolism, and the conceivable function of cis-zeatin-type cytokinins in plants. J. Expt. Bot. 62:2827-2840.

Kiba, T., T. Kudo, M. Kojima, and H. Sakakibara. 2011. Hormonal control of nitrogen acquisition: Roles of auxin, abscisic acid, and cytokinin. J. Expt. Bot. 62:1399-1409.

Korus, K., M.E. Conley, E.E. Blankenship, and E.T. Paparozzi. 2010. Storage and breakdown of starch aid $P$. parviflorus in leaf regreening after nitrogen deficiency. Rev. Undergraduate Res. Agr. Life Sci. 15:1-16.

Littell, R.C., G.A. Milliken, W.W. Stroup, R.D. Wolfinger, and O. Schabenberger. 2006. SAS ${ }^{\circledR}$ for mixed models. SAS Inst., Cary, NC. Milliken, G.A. and D.E. Johnson. 2009. Analysis of messy data. Volume 1. Designed experiments. 2nd ed. Chapman Hall/CRC, Boca Raton, FL.

Pavlíková, D., M. Neuberg, E. Žižková, V. Motyka, and M. Pavlík. 2012. Interactions between nitrogen nutrition and phytohormone levels in Festulolium plants. Plant Soil Environ. 58:367-372.

Ruffel, S., G. Krouk, D. Ristova, D. Shasha, K.D. Birnbaum, and G.M. Coruzzi. 2011. Nitrogen economics of root foraging: Transitive closure of the nitrate-cytokinin relay and distinct systemic signaling for N supply vs. demand. Proc. Natl. Acad. Sci. USA 108:18524-18529. 
Salama, A. and P.F. Wareing. 1979. Effects of mineral nutrition on endogenous cytokinins in plants of sunflower (Helianthus annuus L.). J. Expt. Bot. 30:971-981.

Samuelson, M.E. and C.M. Larsson. 1993. Nitrate regulation of zeatin riboside levels in barley roots - Effects of inhibitors of $\mathrm{N}$-assimilation and comparison with ammonium. Plant Sci. 93:77-84.

Spichal, L., N.Y. Rakova, M. Riefler, T. Mizuno, G.A. Romanov, M. Strnad, and T. Schmulling. 2004. Two cytokinin receptors of Arabidopsis thaliana, CRE1/AHK4 and AHK3, differ in their ligand specificity in a bacterial assay. Plant Cell Physiol. 45:1299-1305.
Takei, K., H. Sakakibara, and T. Sugiyama. 2001a. Identification of genes encoding adenylate isopentenyl transferase, a cytokinin biosynthesis enzyme, in Arabidopsis thaliana. J. Biol. Chem. 276:26405-26410.

Takei, K., H. Sakakibara, M. Taniguchi, and T. Sugiyama. 2001b. Nitrogen-dependent accumulation of cytokinins in root and the translocation to leaf: Implication of cytokinin species that induces gene expression of maize response regulator. Plant Cell Physiol. 42:85-93.

Wang, R.C., R. Tischner, R.A. Gutierrez, M. Hoffman, X.J. Xing, M.S. Chen, G. Coruzzi, and N.M. Crawford. 2004. Genomic analysis of the nitrate response using a nitrate reductase-null mutant of Arabidopsis. Plant Physiol. 136:2512-2522. 